\title{
N-3-oxo-hexanoyl-homoserine lactone, a bacterial quorum sensing signal, enhances salt tolerance in Arabidopsis and wheat
}

\author{
Qian Zhao ${ }^{1,3 \dagger}$, Xiang-Yun Yang ${ }^{2 \dagger}$, Yao Li ${ }^{1}$, Fang Liu ${ }^{1,3}$, Xiang-Yu Cao ${ }^{1}$, Zhen-Hua Jia ${ }^{1,3}$ and Shui-Shan Song ${ }^{1,3^{*}}$
}

\begin{abstract}
Background: $\mathrm{N}$-acyl-homoserine lactones (AHLs) are the quorum sensing (QS) signal molecules to coordinate the collective behavior in a population in Gram-negative bacteria. Recent evidences demonstrate their roles in plant growth and defense responses.

Results: In present study, we show that the treatment of plant roots with $\mathrm{N}$-3-oxo-hexanoyl-homoserine lactone (3OC6-HSL), one molecule of AHLs family, resulted in enhanced salt tolerance in Arabidopsis and wheat. We found that the growth inhibition phenotype including root length, shoot length and fresh weight were significantly improved by 30C6-HSL under salt stress condition. The physiological and biochemical analysis revealed that the contents of chlorophyll and proline were increased and the contents of MDA and $\mathrm{Na}^{+}$and $\mathrm{Na}^{+} / \mathrm{K}^{+}$ratios were decreased after 30C6-HSL treatment in Arabidopsis and wheat under salt stress condition. Molecular analysis showed that 3OC6-HSL significantly upregulated the expression of salt-responsive genes including ABA-dependent osmotic stress responsive genes COR15a, RD22, ADH and P5CS1, ABA-independent gene ERD1, and ion-homeostasis regulation genes SOS1, SOS2 and SOS3 in Arabidopsis under salt stress condition.
\end{abstract}

Conclusions: These results indicated that 30C6-HSL enhanced plant salt tolerance and ABA-dependent and ABAindependent signal pathways and SOS signaling might be involved in the induction of salt resistance by 3OC6-HSL in plants. Our data provide a new insight into the plant-microbe inter-communication.

Keywords: N-acyl-homoserine lactone, Quorum sensing, Salt tolerance, Arabidopsis, Wheat

\section{Background}

$N$-acyl-homoserine lactones (AHLs) are produced by many Gram-negative bacteria to communicate and coordinate the individual behavior in a cell densitydependent manner in bacterial populations. This signaling mechanism is called quorum sensing (QS). Bacterial QS is involved in many physiological processes, such as virulence, bioluminescence, sporulation, swarming, siderophore production, antibiotic biosynthesis, biofilm formation and plasmid conjugal transfer (Pearson et al.

\footnotetext{
*Correspondence: shuishans620@163.com

${ }^{\dagger}$ Qian Zhao and Xiang-Yun Yang contributed equally to this work

1 Biology Institute, Hebei Academy of Sciences, 46th South Street of

Friendship, Shijiazhuang 050051, Hebei, China

Full list of author information is available at the end of the article
}

1994; Parsek et al. 1999). In recent years, accumulating evidence indicates that AHLs also have an impact on plant cells (Mathesius et al. 2003; von Rad et al. 2008; Liu et al. 2012; Miao et al. 2012; Schikora et al. 2011; Shenk et al. 2014; Zhao et al. 2015, 2016). Plants change their gene expression, alter their protein profile, modify their development and enhance their defense responses if AHLs are present in their surroundings. Proteomic analysis has revealed that the expression of over 150 proteins were significant changed after treated with two different AHL types, N-3-oxo-dodecanoyl-homoserine lactone (3OC12-HSL) and N-3-oxo-hexadecanoyl-homoserine lactone (3OC16:1-HSL) in Medicago truncatula (Mathesius et al. 2003), and the level of 53 proteins were accumulated induced by $\mathrm{N}$-3-oxo-octanoyl-homoserine 
lactone (3OC8-HSL) in Arabidopsis seedlings (Miao et al. 2012). These proteins were found to function in plant defense, stress response, flavonoid synthesis, plant hormone responses, the cytoskeleton, protein degradation and processing, energetics and metabolic activities (Mathesius et al. 2003; Miao et al. 2012). Microarray analysis revealed that transcriptional changes in 1816 genes were induced by $N$-hexanol-homoserine lactone (C6-HSL) (von Rad et al. 2008) and a total of 2873 genes were differentially expressed in response to $\mathrm{N}$-3-oxohexanol-homoserine lactone (3OC6-HSL) (Zhao et al. 2016) in Arabidopsis. The majority of the differentially expressed genes could be assigned to the categories of energy metabolism, transcription/translation, biotic/abiotic stress adaptation, protein processing, signal transduction and hormone response (von Rad et al. 2008; Zhao et al. 2016). The short-chained AHLs such as C6-HSL, 3OC6-HSL and 3OC8-HSL can enhance primary root growth of Arabidopsis (von Rad et al. 2008; Jin et al. 2012; Liu et al. 2012; Zhao et al. 2015, 2016). Evidence suggested that G-protein, $\mathrm{Ca}^{2+} / \mathrm{CaM}$ signaling and transcriptional factor MYB44 are involved in AHL-induced primary root elongation (Liu et al. 2012; Song et al. 2011; Zhao et al. 2015, 2016). N-3-oxo-decanoyl-homoserine lactone (3OC10-HSL) influences the formation of adventitious roots via $\mathrm{H}_{2} \mathrm{O}_{2}$ - and NO-dependent cGMP signaling in mung beans (Bai et al. 2012). N-decanoylhomoserine lactone $(\mathrm{C} 10-\mathrm{HSL})$ inhibited the primary root growth but stimulated the lateral root and root hair development (Ortiz-Castro et al. 2008). N-3-oxo-tetradecanoyl-Lhomoserine lactone (3OC14-HSL) significantly enhances the resistance against the bacterial pathogen Pseudomonas syringae pv. tomato DC3000 in Arabidopsis, and similar observations have been made in the case of biotrophic fungal pathogens (Schikora et al. 2011). Evidence suggested that mitogen-activated protein kinase AtMPK6, salicylic acid (SA) and oxylipin are required for AHL-induced resistance (Schikora et al. 2011; Shenk et al. 2014).

Salinity is a main environmental factor influencing plant growth and crop yield. High salt concentration in soil has a devastating effect on plant metabolism, disrupting cellular homeostasis and uncoupling major physiological and biochemical processes (Zou et al. 2019). Plants evolved a ubiquitous mechanism of salinity resistance, involving synthesis and accumulation of compatible compounds, sodium sequestration in vacuoles, enhancing antioxidant enzymes activities and so on (Zou et al. 2019). Salinity resistance can be further improved through the application of exogenous biostimulants (Bose et al. 2014). A plant biostimulant is a substance or microorganism that is beneficial to plants as growth promoters and stress protectors, regardless of its own nutrient content (Zou et al. 2019). Various biostimulants have been used in commercial agriculture, such as humic and fulvic acids, protein hydrolysates and other $\mathrm{N}$-containing compounds, seaweed extracts and botanicals, chitosan and other biopolymers, inorganic compounds, beneficial fungi and bacteria (Du Jardin 2015). Rhizosphere bacteria can help plants tolerate abiotic stress, such as drought, salt, extreme temperature, nutrient deficiency and heavy metal toxicity (Dimkpa et al. 2009; Yang et al. 2009; Zhang et al. 2008). 'Induced systemic tolerance' (IST) was proposed for plant growth-promoting rhizobacteria (PGPR)-induced physical and chemical changes in plants that result in enhanced tolerance to abiotic stress (Yang et al. 2009). Inoculation of tomato plants with AHL-producing Burkholderia graminis M14 conferred dramatic protection against salt stress, and the transgenic tomato lines expressing YenI (short-chain AHL producers) and LasI (long-chain AHL producers) exhibited salt tolerance (Barriuso et al. 2008). AHLs were considered as priming inducer to sensitize plant hosts to have the faster and the stronger responses to resist the subsequent stresses (Shenk and Schikora 2015). Proteomics analysis show that $23 \%$ of changed proteins induced by $3 \mathrm{OC} 12-\mathrm{HSL}$ and 3OC16:1-HSL related to defence response and stress response in Medicago truncatula (Mathesius et al. 2003). Microarray analysis show that $14.3 \%$ of the different expressing genes induced by 3OC6-HSL related to abiotic stress responses and the expression of 62 salt responsive genes were regulated in Arabidopsis seedlings (Zhao et al. 2016). However, little is known about the function of bacteria AHLs to the plant response to salt stress.

In present study, the effect of bacterial QS signal 3OC6HSL on plant salt tolerance were analyzed in Arabidopsis and wheat. Shoot and root growth parameters, photosynthetic pigment, biochemical markers and ion contents were determined, and possible molecular mechanism of 3OC6-HSL-mediated salt tolerance was discussed in Arabidopsis and wheat.

\section{Methods}

\section{Plant materials and growth conditions}

Arabidopsis thaliana (L.) cv. Columbia-0 seeds were surface-sterilized by $75 \%(\mathrm{v} / \mathrm{v})$ ethanol and $20 \%(\mathrm{v} / \mathrm{v})$ $\mathrm{NaClO}$ and geminated on Murashige and Skoog (MS) Polygel medium (Murashige and Skoog 1962) adjusted to $\mathrm{pH} 5.8$. The seeds were stratified at $4{ }^{\circ} \mathrm{C}$ for 2 days and then grown in a growth chamber at $22 \pm 2{ }^{\circ} \mathrm{C}$ and a $16 \mathrm{~h}$ light $/ 8 \mathrm{~h}$ dark cycle with light intensity of $100 \mu \mathrm{mol} \mathrm{m} \mathrm{m}^{2} \mathrm{~s}^{-1}$. Sterile Hoagland medium were used for hydroponics and fertilized substrate TS1 (KlasmannDeilmann GmbH, Germany) and vermiculite (1:2) were used for soil culture. 
Wheat (Triticum aestivum L.) seeds were surface-sterilized by $75 \%(\mathrm{v} / \mathrm{v})$ ethanol and soaked in water until germination, then transplanted into a floating hydroponic system containing sterile water at $25 \pm 2{ }^{\circ} \mathrm{C}$ and under 16/8-h photoperiod (light/dark) with light intensity of $100 \mu \mathrm{mol} \mathrm{m}^{2} \mathrm{~s}^{-1}$.

\section{$\mathrm{N}$-acyl-homoserine lactones $(\mathrm{AHL})$ and salt stress treatments}

The AHL, N-( $\beta$-ketocaproyl)-DL-homoserine lactone (3OC6-HSL), was purchased from Sigma-Aldrich (Deisenhofen, Germany), stored dry and diluted as $10 \mathrm{mM}$ stock solutions in $\mathrm{dH}_{2} \mathrm{O}$ and sterilized by passing them through a $0.22-\mu \mathrm{m}$ filter just prior to use. Solutions of $1 \mu \mathrm{M}$ 3OC6-HSL or/and $150 \mathrm{mM} \mathrm{NaCl}$ were used as the treatments in our experiments. The untreated plants were taken as the control.

\section{Measurement of growth parameters}

For primary root growth assay, Arabidopsis seeds were germinated vertically on MS Polygel plates for 3 days, then the seedlings with similar root length were selected to transfer to $1 / 2 \mathrm{MS}$ Polygel plates containing $1 \mu \mathrm{M}$ 3OC6-HSL or/and $150 \mathrm{mM} \mathrm{NaCl}$. After cultured vertically for 6 days, primary root length was assessed using Image J software. The seeds of wheat were germinated and grown on sterile water containing $1 \mu \mathrm{M}$ 30C6HSL or/and $150 \mathrm{mM} \mathrm{NaCl}$ for 6 days, then the root and shoot length were assessed using Image J software. The untreated plants were taken as the control. The experiments were replicated three times and each biological replication included at least 30 seedlings for each treatment.

For seedling-growth assay, 10 day-old seedlings of Arabidopsis on MS Polygel plates were transplanted into nutrition pots and 2 week-old soil-cultured seedlings were treated with $1 \mu \mathrm{M}$ 3OC6-HSL or/and $150 \mathrm{mM}$ $\mathrm{NaCl}$. After 14 days, phenotypic changes of the seedlings were observed and the shoot length and fresh weight were measured. 2 week-old seedlings of wheat at the stage of two leaves and one shoot were treated with $1 \mu \mathrm{M}$ 3OC6-HSL or/and $150 \mathrm{mM} \mathrm{NaCl}$ for 10 days, and the shoot length and fresh weight were measured. The untreated plants were taken as the control. The experiments were replicated four times and each biological replication included 15-30 seedlings for each treatment.

\section{Chlorophyll content}

Chlorophyll content was determined according to Arnon (1949). 2 week-old Arabidopsis and wheat seedlings were treated with $1 \mu \mathrm{M}$ 3OC6-HSL or/and $150 \mathrm{mM} \mathrm{NaCl}$ for 14 days in Arabidopsis and 10 days in wheat, and then harvested for chlorophyll determination. Untreated plants were used as controls. Total chlorophyll (Chl $a+b)$ were extracted from fresh leaf samples in $80 \%$ $(\mathrm{v} / \mathrm{v})$ acetone. The absorbance at $663 \mathrm{~nm}$ and $645 \mathrm{~nm}$ was measured using the UV-VIS spectrophotometer (model UV-2600, Shimadzu, Japan). The experiments were replicated three times and each biological replication included three replicated samples.

\section{Proline content}

Proline content determination was performed as reported previously (Bates et al. 1973) with minor modification. 2 week-old Arabidopsis and wheat seedlings were treated with $1 \mu \mathrm{M}$ 3OC6-HSL or/and $150 \mathrm{mM}$ $\mathrm{NaCl}$ for 14 days in Arabidopsis and 10 days in wheat, and then harvested for proline determination. Untreated plants were used as controls. $100 \mathrm{mg}$ fresh shoot samples were homogenized in $1.5 \mathrm{ml}$ of $0.3 \%$ (w/v) sulphosalicylic acid, then centrifuged at $10,000 \times g$ for $10 \mathrm{~min}$. $100 \mu \mathrm{l}$ of supernatant was reacted with $1 \mathrm{ml}$ glacial acetic acid and $1 \mathrm{ml}$ acid ninhydrin at $100{ }^{\circ} \mathrm{C}$ for $30 \mathrm{~min}$, and cooled on ice to terminate the reaction. Then the reaction mixture was extracted with $1 \mathrm{ml}$ toluene and the absorbance at $520 \mathrm{~nm}$ were measured using the UV-VIS spectrophotometer (model UV-2600, Shimadzu, Japan). Proline concentration was determined by the proline standard curve. The experiments were replicated three times and each biological replication included three replicated samples.

\section{Lipid peroxidation}

Amount of lipid peroxidation was determined by estimating the malondialdehyde (MDA) produced by the thiobarbituric acid (TBA) reaction according to Del Buono et al. (2011) with minor modification. 2 week-old Arabidopsis and wheat seedlings were treated with $1 \mu \mathrm{M}$ 3OC6-HSL or/and $150 \mathrm{mM} \mathrm{NaCl}$ for 14 days in Arabidopsis and 10 days in wheat, and then harvested for MDA determination. Untreated plants were used as controls. $100 \mathrm{mg}$ fresh shoot samples were homogenized with $10 \%$ $(\mathrm{w} / \mathrm{v}) \mathrm{TCA}$ and centrifuged at $4000 \times g$ for $10 \mathrm{~min} .1 \mathrm{ml}$ of $0.6 \%(\mathrm{w} / \mathrm{v})$ TBA was added to $1 \mathrm{ml}$ of supernatant. The mixture was heated at $100{ }^{\circ} \mathrm{C}$ for 15 min and immediately cooled on ice, then centrifuged at $10,000 \times g$ for $15 \mathrm{~min}$. Absorbance at 450, 532 and $600 \mathrm{~nm}$ were measured using the UV-VIS spectrophotometer (model UV-2600, Shimadzu, Japan). The experiments were replicated three times and each biological replication included three replicated samples.

\section{Measurement of $\mathrm{Na}^{+}$and $\mathrm{K}^{+}$concentrations}

Atomic absorption was used to determine the $\mathrm{Na}^{+}$and $\mathrm{K}^{+}$content, as conducted by Zhao et al. (2009). 2 weekold Arabidopsis and wheat seedlings were treated with $1 \mu \mathrm{M}$ 3OC6-HSL or/and $150 \mathrm{mM} \mathrm{NaCl}$ for 14 days in 
Arabidopsis and 10 days in wheat, and then harvested for ion determination. Untreated plants were used as controls. Shoot samples were dried at $80{ }^{\circ} \mathrm{C}$ for $48 \mathrm{~h} .50 \mathrm{mg}$ dry samples were digested with $3 \mathrm{ml}$ of nitric acid, and $\mathrm{Na}^{+}$and $\mathrm{K}^{+}$concentrations were determined with an atomic absorption spectrometer (model A240FS + 240Z; Varian, Palo Alto, CA). The experiments were replicated three times and each biological replication included three replicated samples.

\section{Quantitative Real-Time (qRT) PCR analysis}

20 day-old hydroponic cultured Arabidopsis seedlings were treated with $1 \mu \mathrm{M}$ 3OC6-HSL or/and $150 \mathrm{mM} \mathrm{NaCl}$ for $6 \mathrm{~h}$ and then harvested for RNA extraction. Untreated plants were used as controls. Total RNA was extracted using the RNAiso Plus reagent (TaKaRa, Dalian, China). cDNA was synthesized using the PrimeScript ${ }^{\circledR}$ RT Reagent Kit with gDNA Eraser (TaKaRa, Dalian, China) according to the manufacturer's instructions. SYBR Premix Ex Taq was purchased from TaKaRa (Shiga, Japan). For the relative quantification of gene expression, the comparative $C_{T}$ method (Livak and Schmittgen 2001) was used with the 7500 Real Time PCR System (Applied Biosystems, Foster City, CA, USA). The amount of target was normalized to the endogenous reference gene ACTIN2. For technical control, each sample was repeated four times on the same 96-well plate. Each data point represents the average of three independent experiments. A 1.5-fold increase (ratio $>1.5$ ) or 1.5-fold decrease (ratio $<0.8$ ) in expression in the treated plants compared with the untreated plants (the control) was considered as up-regulation or down-regulation related to stress response. The specific primers that we used for qRT-PCR are shown in Additional file 1: Table S1.

\section{Statistical analysis}

For all experiments, the overall data were statistically analyzed in the DPS v7.05 program. Univariate and multivariate analyses (ANOVA) with a Duncan's new multiple range tests $(P<0.05)$ were used. All data were represented as mean $\pm S D$ of three or four independent experiments.

\section{Results}

\section{C6-HSL is helpful to plant growth under salt stress}

The influence of bacterial QS signal 3OC6-HSL on seedling growth of Arabidopsis and wheat were analyzed in both saline and non-saline environment. Application of 3OC6-HSL can significantly enhance plant growth in both Arabidopsis and wheat under non-saline condition (Fig. 1a). Compared with the untreated control, the shoot length increased by $15.6 \%$ and $19.2 \%$ (Fig. 1b, d), and the fresh weight increased by $14.4 \%$ and $23.7 \%$ (Fig. 1c, e) in
30C6-HSL-treated Arabidopsis and wheat, respectively. Under salt stress condition, the phenotype of dwarf and yellow wilt caused by high salinity were significantly improved by 3OC6-HSL in both Arabidopsis and wheat (Fig. 1a). Compared with the $\mathrm{NaCl}$-treated plants, the shoot length increased by $25.5 \%$ and $22.4 \%$ (Fig. 1b, d) and the fresh weight increased by $30.6 \%$ and $29.9 \%$ (Fig. 1c, e) in 3OC6-HSL and $\mathrm{NaCl}$ co-treated Arabidopsis and wheats, respectively. These results indicated that 3OC6-HSL played an important role in plant growth under salt stress.

30C6-HSL promotes plant root elongation under salt stress The effect of 3OC6-HSL on root growth of Arabidopsis and wheat were analyzed in both saline and non-saline environment. 3OC6-HSL induced plant root elongation significantly under non-saline condition (Fig. 2a, b, e, f) and relieved root growth inhibition significantly under salt stress condition (Fig. 2c, d, g, h) in both Arabidopsis and wheat. Compared with the non-3OC6-HSL-treated plants, the primary root length increased by $43.7 \%$ and $55.1 \%$ in 3OC6-HSL-treated Arabidopsis under nonsaline and saline condition, respectively (Fig. 2i). Similarly, the root length increased by $10.1 \%$ and $50.1 \%$ and the shoot length increased by $25.8 \%$ and $89.9 \%$ in 3OC6-HSL-treated wheat under non-saline and saline condition, respectively, compared with those of non3OC6-HSL-treated plants (Fig. 2j, k). These results indicated that 3OC6-HSL played a positive role in plant early growth and root elongation under salt stress.

\section{C6-HSL influents biochemical markers related to plant salt tolerance}

The effect of 3OC6-HSL on biochemical markers related to plant salt tolerance, including chlorophyll, proline and MDA, were analyzed in Arabidopsis and wheat under both saline and non-saline condition.

Chlorophyll level is widely used as an index of abiotic stress tolerance in plant. Compared with the control plants, total chlorophyll (chla + chlb) content increased by $21.1 \%$ and $27.3 \%$ in 3OC6-HSL-treated Arabidopsis and wheat, respectively (Fig. 3a, d). And compared with $\mathrm{NaCl}$-treated plants, total chlorophyll content increased by $34.9 \%$ and $43.1 \%$ in $3 \mathrm{OC} 6-\mathrm{HSL}$ and $\mathrm{NaCl}$ co-treated Arabidopsis and wheat, respectively (Fig. 3a, d). 30C6HSL induced a significant raise of total chlorophyll content under non-saline condition and relieved significantly the decrease of total chlorophyll content caused by high salinity in both Arabidopsis and wheat.

Accumulation of osmolyte proline facilitates plant to overcome abiotic stress by maintaining osmotic turgor (Tiwari et al. 2017). There were no significant changes in proline content among 3OC6-HSL-treated and 
a
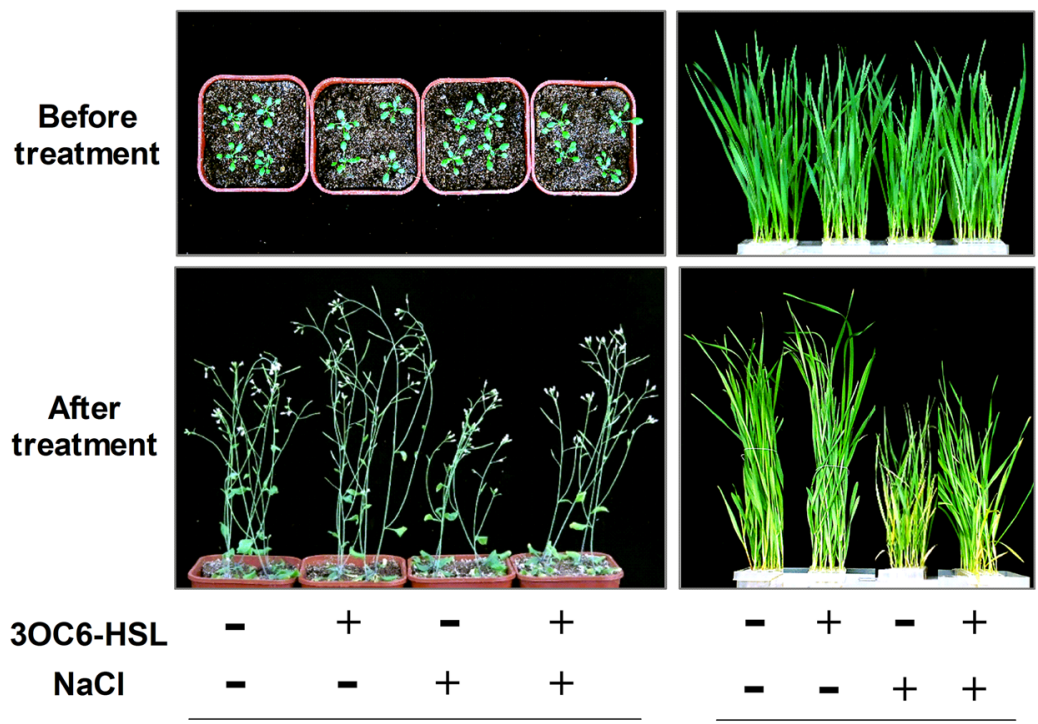

$$
\mathrm{NaCl}
$$

\section{Arabidopsis}

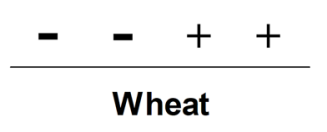

b

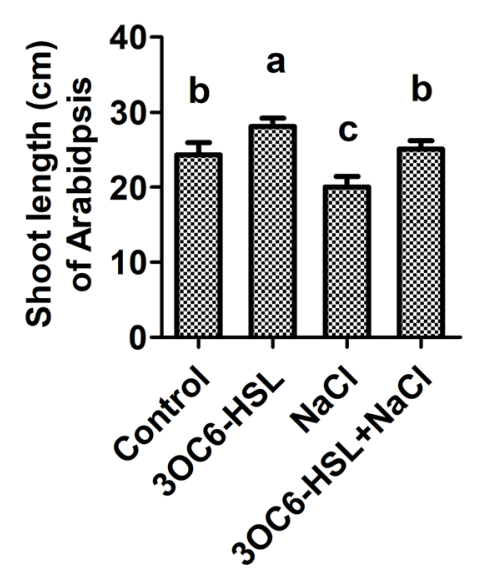

d

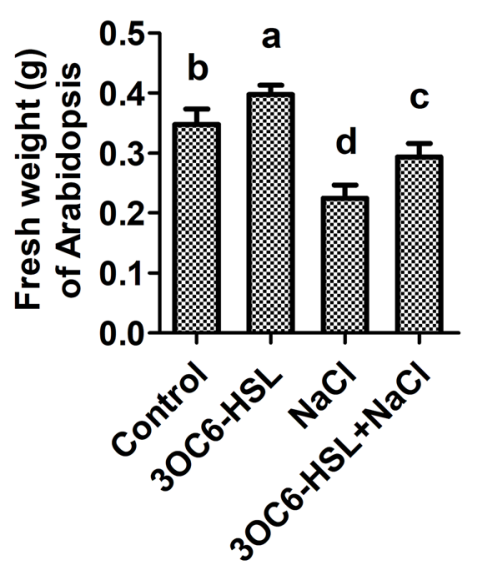

c

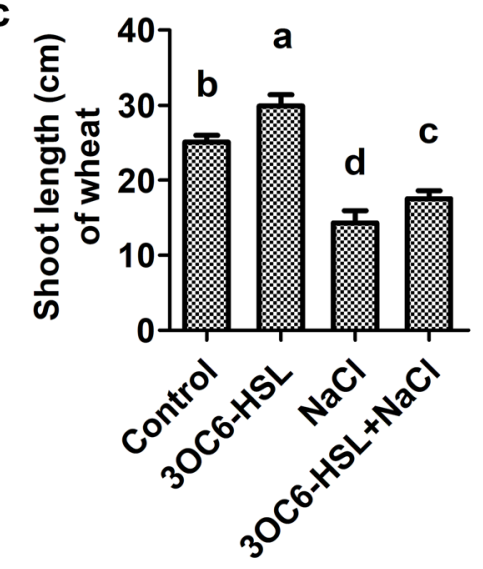

e

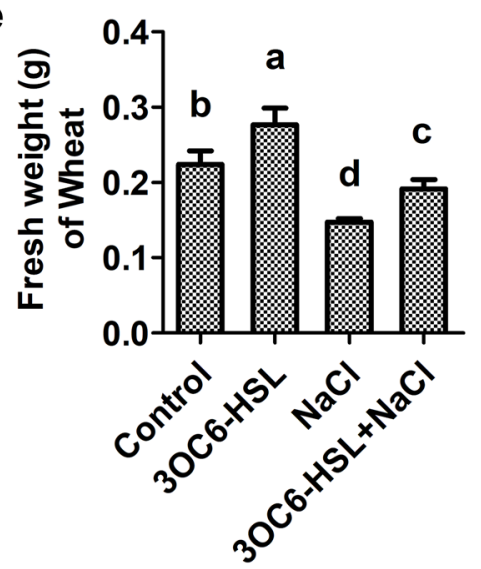

Fig. 1 Effect of 3OC6-HSL on plant growth in Arabidopsis and wheat. 2-week-old seedlings were treated with 1 MM 30C6-HSL or/and 150 mM $\mathrm{NaCl}$ as indications. The changes of plant growth phenotype were observed after treatment for 14 days in Arabidopsis and 10 days in wheat. a Plant growth status; $\mathbf{b}$ shoot length of Arabidopsis; $\mathbf{c}$ fresh weight of Arabidopsis; $\mathbf{d}$ shoot length of wheat; $\mathbf{e}$ fresh weight of wheat. Values are mean \pm SD of four independent experiments. Different letters indicate statistically significant differences $(P<0.05$, Duncan's test) 

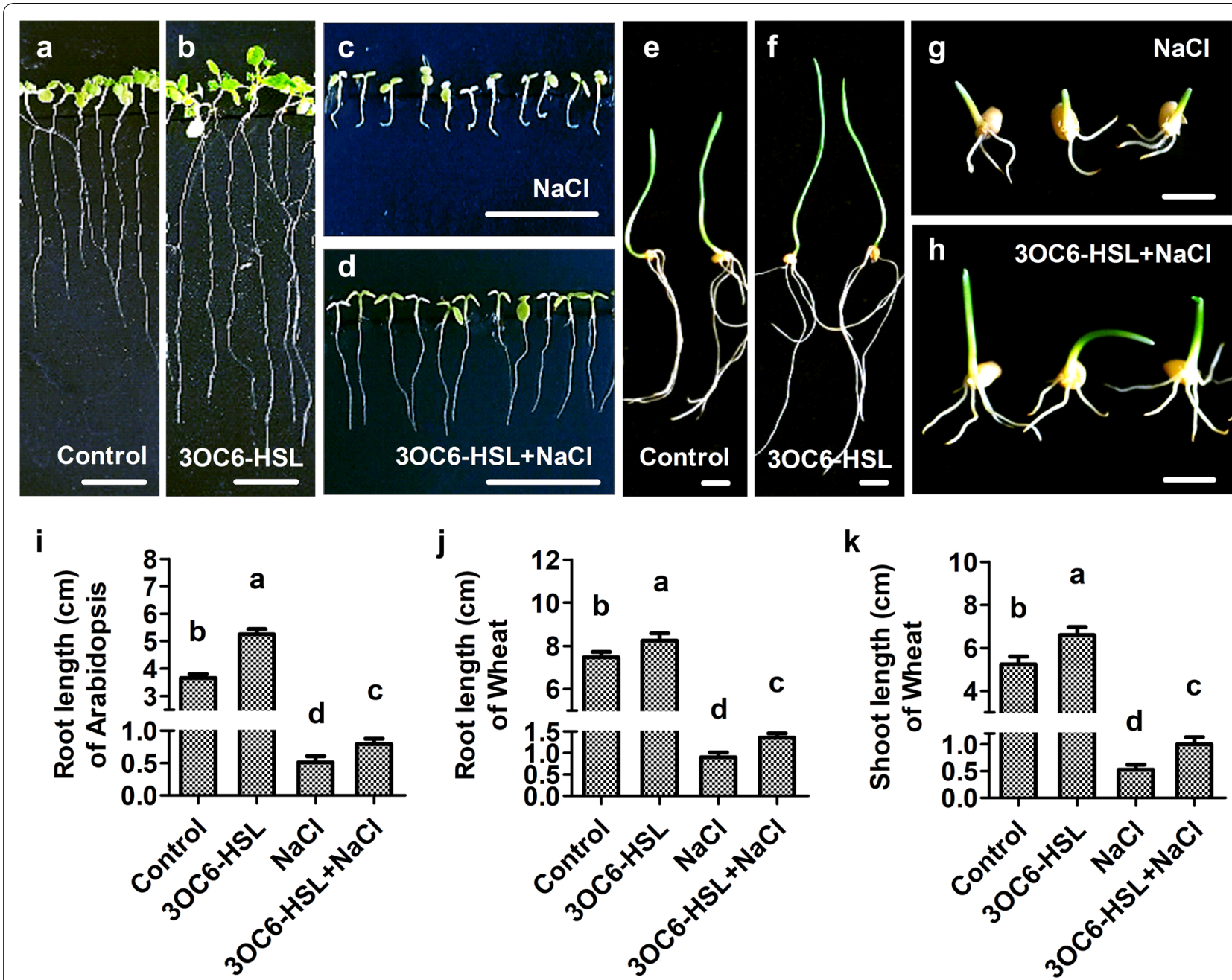

k

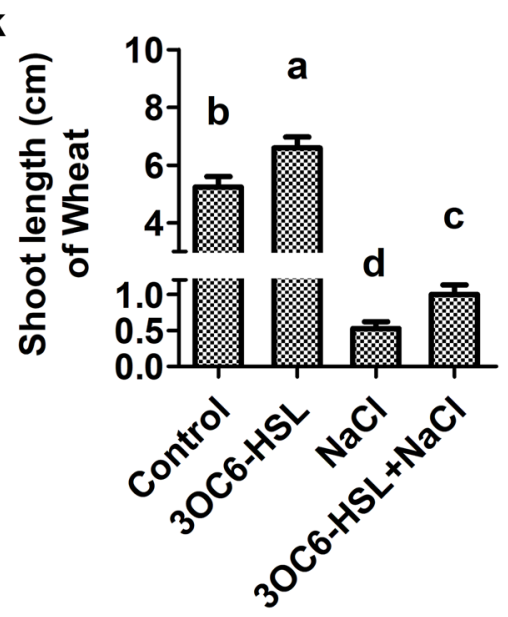

Fig. 2 Effect of 3OC6-HSL on root growth in Arabidopsis and wheat. Seedlings were treated with 1 $\mu$ M 3OC6-HSL or/and 150 mM NaCl after seeds germination. The changes of root phenotype were observed after 6 days treatment in Arabidopsis and wheat. $\mathbf{a}$, e Non-treated control plants; $\mathbf{b}$, f 3OC6-HSL treated plants; $\mathbf{c}, \mathbf{g ~ N a C l}$ treated plants; $\mathbf{d}$, h 30C6-HSL and NaCl co-treated plants; i root length of Arabidopsis; j root length of wheat; $\mathbf{k}$ shoot length of wheat. bar $=1 \mathrm{~cm}$, values are mean $\pm S D$ of three independent experiments. Different letters indicate statistically significant differences $(P<0.05$, Duncan's test)

non-3OC6-HSL-treated Arabidopsis and wheat under non-saline condition, whereas, an increase was registered when plants were exposed in salt environment (Fig. 3b, e). However, a higher level of proline was induced by 3OC6-HSL under salt stress condition, which were increased by $47.4 \%$ and $32.6 \%$ relative to the control in Arabidopsis and wheat, respectively (Fig. 3b, e).

MDA is an indicator of extent of lipid peroxidation and membrane damage in plant during salt stress. Decline of MDA content was observed in Arabidopsis with 30C6HSL treatment, especially under salt stress condition. The ratio of MDA decline was $23.1 \%$ and $64.7 \%$ under non-saline condition and saline condition, respectively, in comparison to the non-3OC6-HSL-treated Arabidopsis
(Fig. 3c). Compared with the non-3OC6-HSL-treated wheat, a slight higher MDA content (26.1\% of increase) was shown in 30C6-HSL-treated wheat under normal condition while significant lower MDA content (64.9\% of decrease) was shown in 30C6-HSL-treated wheat under salt stress condition (Fig. 3f).

30C6-HSL is helpful to modulate the level of cellular $\mathrm{Na}^{+}$ under salt stress

The effect of 3OC6-HSL on cellular ion contents were analyzed in Arabidopsis and wheat under both saline and non-saline condition. There was no significant difference of $\mathrm{Na}^{+}$and $\mathrm{K}^{+}$contents between the control and 3OC6HSL-treated Arabidopsis and wheat under non-saline 

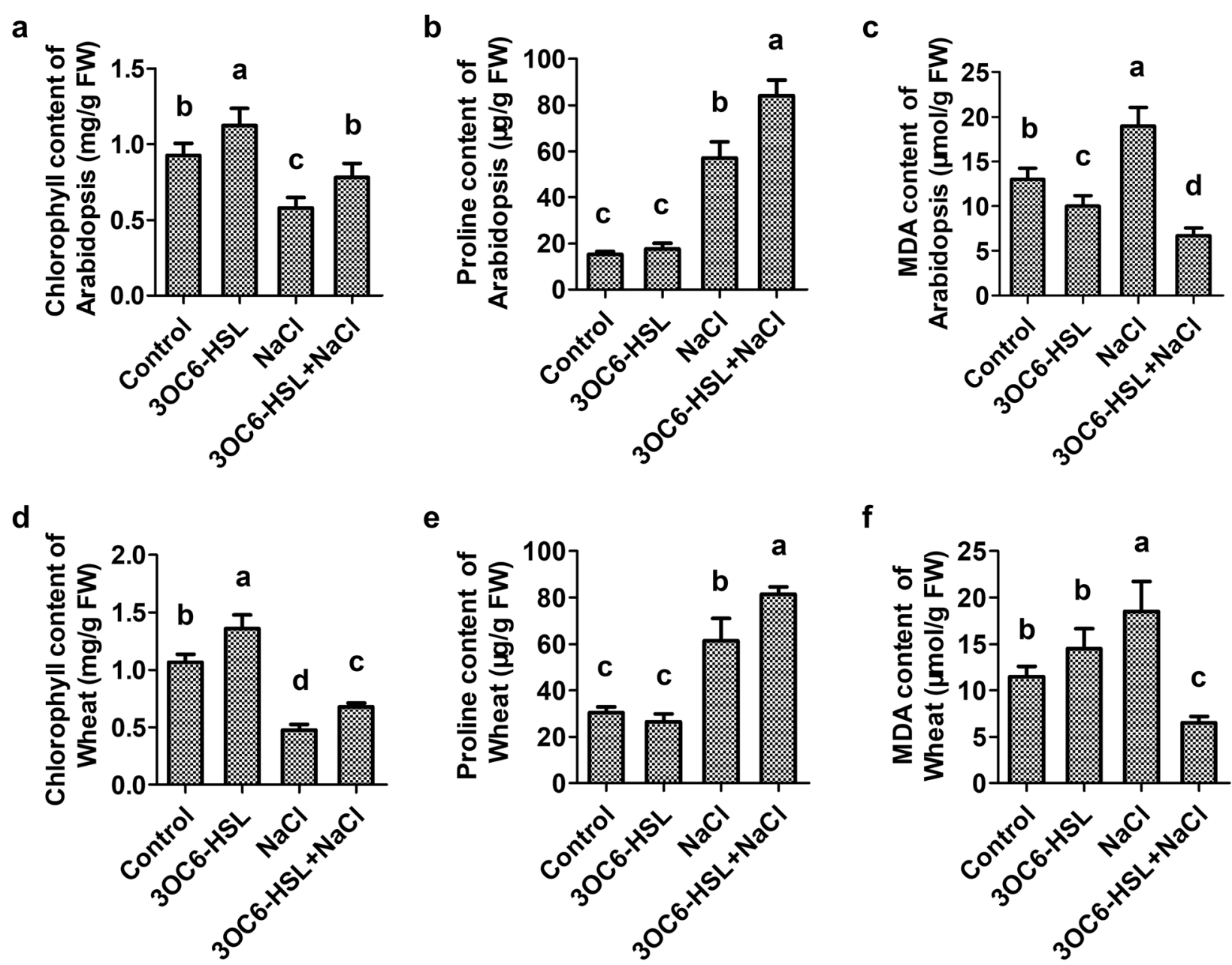

f

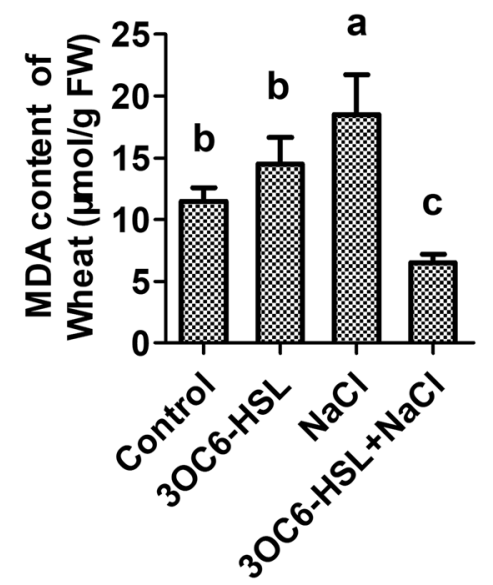

Fig. 3 Effect of 3OC6-HSL on biochemical markers related to salt toleranc in Arabidopsis and wheat. 2-week-old seedlings were treated with $1 \mu \mathrm{M} 30 \mathrm{OC6}-\mathrm{HSL}$ or/and $150 \mathrm{mM} \mathrm{NaCl}$ as indications. The levels of total chorophyll, proline and MDA were measured after treatment for 14 days in Arabidopsis ( $\mathbf{a}-\mathbf{c})$ and 10 days in wheat $(\mathbf{d}-\mathbf{f})$. Values are mean \pm SD of three independent experiments. Different letters indicate statistically significant differences $(P<0.05$, Duncan's test)

condition (Fig. 4a, b, d, e). High salinity led to cellular $\mathrm{Na}^{+}$content increase sharply, while $\mathrm{K}^{+}$content decline. However, high $\mathrm{Na}^{+}$contents reduced significantly with 3OC6-HSL application in Arabidopsis and wheat under salt stress condition. The level of cellular $\mathrm{Na}^{+}$decreased by $52.4 \%$ and $16.7 \%$ in $3 \mathrm{OC} 6-\mathrm{HSL}$ and $\mathrm{NaCl}$ co-treated Arabidopsis and wheat, respectively, compared with $\mathrm{NaCl}$-treated seedlings (Fig. 4a, d). There were no change in $\mathrm{K}^{+}$content after 3OC6-HSL treatment in Arabidopsis and wheat under salt stress condition (Fig. 4b, e). Consequently, lower $\mathrm{Na}^{+} / \mathrm{K}^{+}$ratio was observed in 3OC6-HSL and $\mathrm{NaCl}$ co-treated Arabidopsis and wheat under saline condition (Fig. 4c, f).

For verifying the effect of 3OC6-HSL on cellular ionic homeostasis, the transcriptional expression level of Salt
Overly Sensitive (SOS) pathway genes, including SOS1, SOS2 and SOS3 was analyzed in Arabidopsis under both saline and non-saline condition. The expression of SOS1, SOS2 and SOS3 was up-regulated by 3OC6HSL to 3.8-, 2.3- and 1.8-fold, respectively, compared with untreated control, under non-saline condition (Fig. $4 \mathrm{~g}-\mathrm{i}$ ). There was higher expression level of SOS2 and SOS3 in 3OC6-HSL-treated seedling than in non3OC6-HSL-treated seedling under salt stress condition (Fig. 4h, i). Although no significant change of SOS1 expression level was observed between $\mathrm{NaCl}$-treated seedling and 3OC6-HSL and $\mathrm{NaCl}$ co-treated seedling, 3OC6-HSL could strongly induce SOS1 expression under normal condition (Fig. 4g). 


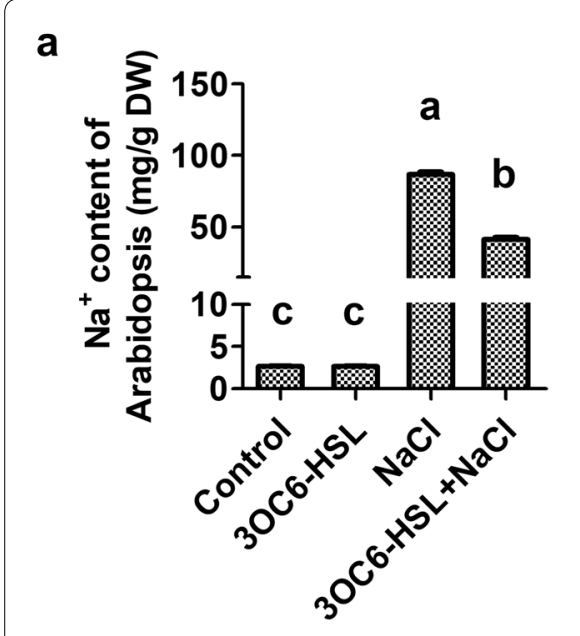

b

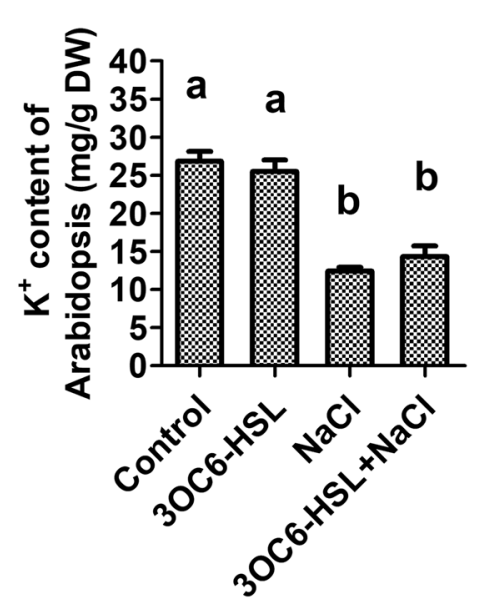

C

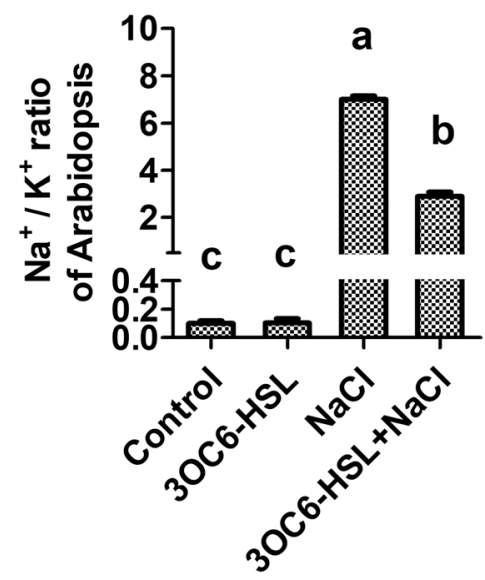

d

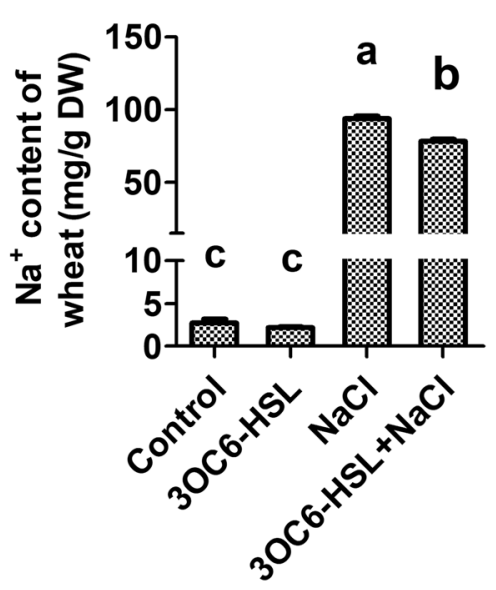

e

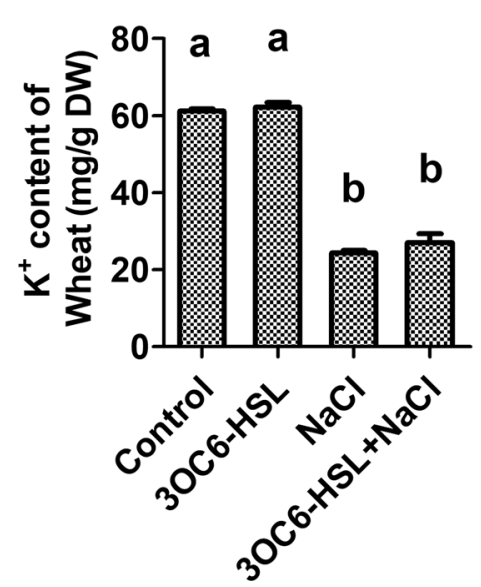

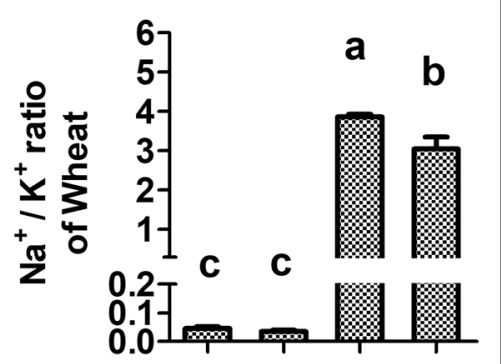

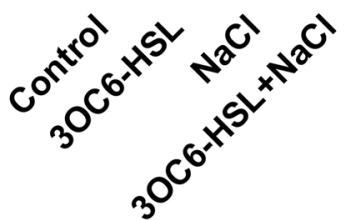

g

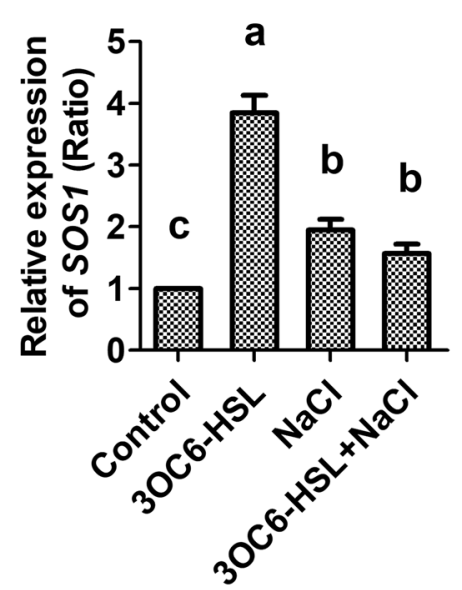

h

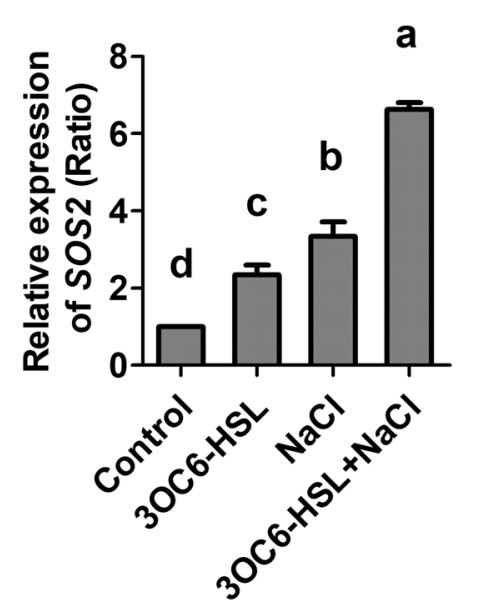

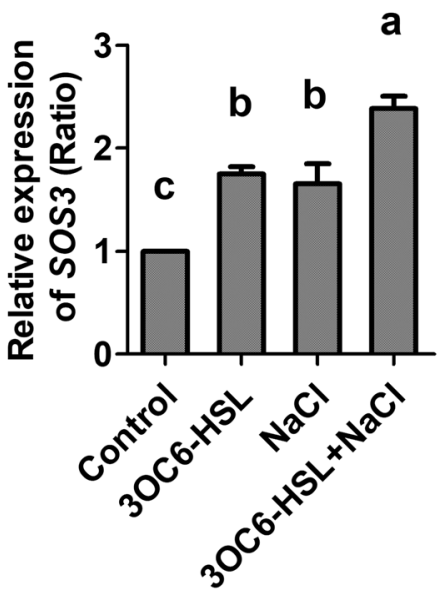

Fig. 4 Effect of 3OC6-HSL on cellular ionic homeostasis in Arabidopsis and wheat. 2-week-old seedlings were treated with 1 HM 3OC6-HSL or/ and $150 \mathrm{mM} \mathrm{NaCl}$ as indications. The contents of $\mathrm{Na}^{+}$and $\mathrm{K}^{+}$were measured and $\mathrm{Na}^{+} / \mathrm{K}^{+}$ratio were calculated after treatment for 14 days in Arabidopsis (a-c) and 10 days in wheat (d-f). 20-day-old seedlings were treated with $1 \mu \mathrm{M}$ 3OC6-HSL or/and $150 \mathrm{mM} \mathrm{NaCl}$ as indications. The relative gene expression of SOS1 (g), SOS2 (h) and SOS3 (i) were measured by qRT-PCR after treatment for $6 \mathrm{~h}$ in Arabidopsis. Values are mean \pm SD of three independent experiments. Different letters indicate statistically significant differences $(P<0.05$, Duncan's test) 
30C6-HSL upregulated the transcriptional expression of both $A B A-d e p e n d e n t$ and $A B A$-independent salt related genes

COR15a, RD22, ADH and P5CS1 genes belonged to ABA-dependent genes in plant salt signaling pathway (Xiong et al. 2001). The expression of COR15a, RD22 and P5CS1 was up-regulated by 3OC6-HSL to 1.8-, 3.4- and 2.6-fold under non-saline condition, respectively, compared with untreated control (Fig. 5a, b, d). There was higher expression level of COR15a and RD22 in 3OC6HSL-treated seedling than in non-3OC6-HSL-treated seedling under salt stress condition (Fig. 5a, b). Although no significant difference of P5CS1 expression level was observed between $\mathrm{NaCl}$-treated seedling and 3OC6-HSL and $\mathrm{NaCl}$ co-treated seedling, 3OC6-HSL could strongly induce P5CS1 expression under normal condition (Fig. 5d). The expression of $A D H$ was not up-regulated by 3OC6-HSL though it could be strongly induced by $\mathrm{NaCl}$ (Fig. 5c).

ERD1 represents ABA-independent gene in plant salt signaling pathway (Nakashima et al. 1997). 3OC6-HSL induced an increased expression of ERD1 by 2.8 -fold compared with untreated control under non-saline condition (Fig. 5e). Under saline condition, the expression of $E R D 1$ was up-regulated significantly by $\mathrm{NaCl}$ and higher expression (2.6-fold compared with $\mathrm{NaCl}$-treated sample) was induced by 3OC6-HSL (Fig. 5e).

\section{Discussion}

Salinity is one of the major abiotic stressors that impairs plant growth and development, for instance, reduction of cell elongation and cell division rates, younger leaves emerge slowly, lateral buds remain quiescent, leaf senescence and flowering starts earlier (Passioura and Munns 2000; Ilangumaran and Smith 2017). Salt tolerance is usually quantified over a given period as survival, vegetative growth, or harvestable biomass at different physiological stages of the plant in saline versus non-saline conditions (Munns 2002). Bacterial QS signal AHLs affect the growth and modulate root structures of dicot and monocot plants. C6-HSL, 3OC6-HSL and 3OC8-HSL promote primary root elongation of Arabidopsis (von Rad et al. 2008; Liu et al. 2012; Zhao et al. 2015). C6-HSL, C8-HSL and C12-HSL promote shoot growth and induce lateral root formation in barley (Klein et al. 2009; Rankl et al. 2016). 3OC10-HSL influences the formation of adventitious roots in mung beans (Bai et al. 2012). Growth promoting effect of AHLs is helpful for plant to withstand environmental stimuli stresses. In present study, effect of 3OC6-HSL on salt tolerance was analyzed in the early and middle vegetative growth period in Arabidopsis and wheat. Application of 3OC6-HSL can significantly
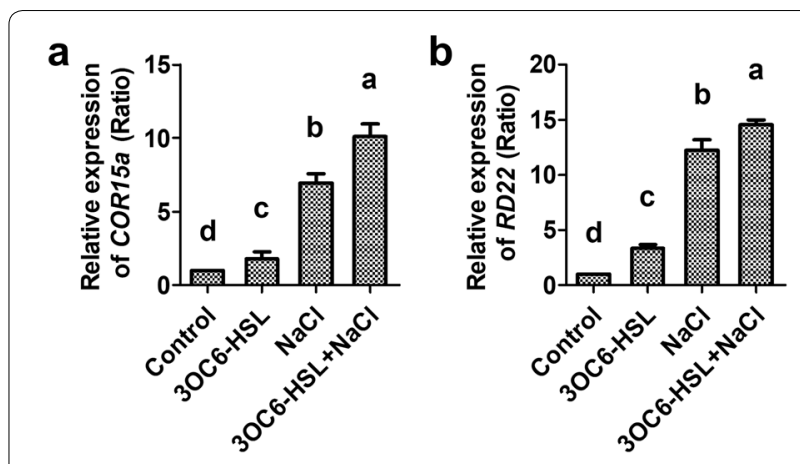

C

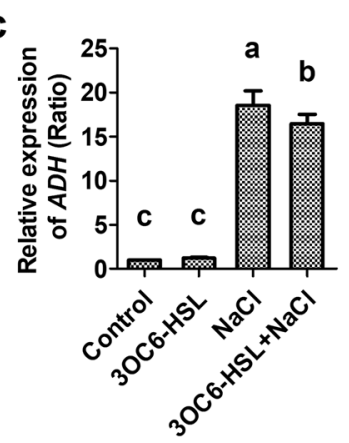

d

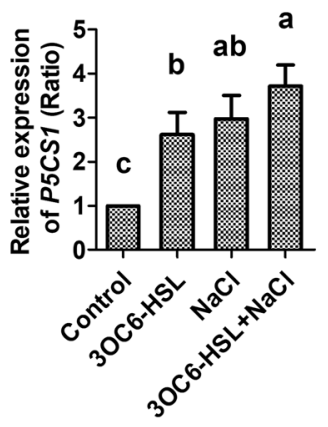

e

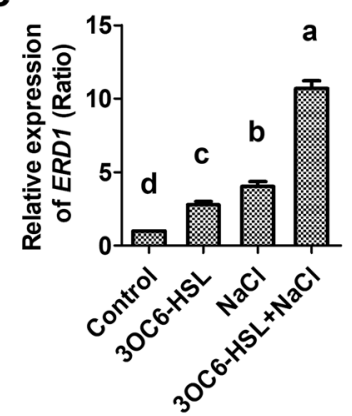

Fig. 5 Effect of 3OC6-HSL on the expression of ABA-dependent and ABA-independent genes in Arabidopsis. 20-day-old seedlings were treated with $1 \mu \mathrm{M}$ 3OC6-HSL or/and $150 \mathrm{mM} \mathrm{NaCl}$ as indications. The relative gene expression of COR15a (a), RD22 (b), ADH (c), P5CS1 (d) and ERD1 (e) were measured by qRT-PCR after treatment for $6 \mathrm{~h}$ in Arabidopsis. Values are mean \pm SD of three independent experiments. Different letters indicate statistically significant differences $(P<0.05$, Duncan's test)

increase the shoot length, root length and fresh weight in Arabidopsis and wheat under both saline and non-saline conditions (Figs. 1b-e and 2i-k). The growth status of dwarf and yellow wilt caused by high salinity were significantly improved by 30C6-HSL treatment (Figs. 1a and 2a-h). Thus, 3OC6-HSL appears to be a potent biostimulator to enhance salt tolerance of Arabidopsis and wheat mainly because of its effect on growth promotion.

Salinity restricts plant growth and development by influencing physiological and biochemical processes. Abiotic stresses seriously affect photosynthesis in plant, 
such as reduction in chlorophyll content, disintegration of chloroplast membranes and disruption of photosystem biochemical reactions (Zou et al. 2019). To increase chlorophyll content is helpful to improve plant growth in saline environment and enhance plant salt tolerance (Zou et al. 2019). Degradation of chlorophyll under abiotic stress is usually related to the accumulation of ROS, which leads to lipid peroxidation of chloroplast membranes (Zou et al. 2019). MDA is an indicator of extent of lipid peroxidation and membrane damage in plant (Lata et al. 2011). In present study, 3OC6-HSL significantly increased chlorophyll content and decreased MDA content in Arabidopsis and wheat under both saline and non-saline condition (Fig. 3a, d). These results indicated that 3OC6-HSL played an important role in enhancing photosynthetic efficiency of plant and protecting plant from membrane destruction.

Plant salt stress can be divided into early-occurring osmotic stress stage and slowly increasing ionic stress stage (Sahi et al. 2006; Munns and Tester 2008). The accumulation of organic osmolytes such as proline, glycine betaine, suger alcohols, polyamines and so on, plays a key role in maintaining the low intracellular osmotic potential of plants and preventing the harmful effects of salt stress (Verslues et al. 2006). Proline not only plays a crucial role in osmotic adjustment but also acts as a reactive oxygen scavenger, redox buffer, or molecular chaperone, stabilizing proteins and membrane structures under stress conditions (Ashraf and Foolad 2007; Verbruggen and Hermans 2008). Proline also induced the expression of salt stress-responsive genes, which promoted the adaptation of plants to salt stress (Zhang et al. 2017). In Arabidopsis, knockout of the P5CS1 gene, which encodes a 1-pyrroline-5-carboxylate synthetase that central for proline biosynthesis, impairs proline synthesis resulting in salt hypersensitivity (Székely et al. 2008). In present study, 3OC6-HSL increased the content of proline significantly and up-regulated the expression of P5CS1 in Arabidopsis and wheat under non-saline and saline conditions, though there was no significant difference in the expression of P5CS1 between $\mathrm{NaCl}$ treated and 3OC6$\mathrm{HSL}$ and $\mathrm{NaCl}$ co-treated seedlings under salt stress (Fig. 3b, e). These results indicated that 3OC6-HSL can activate proline biosynthesis and osmotic modulation in plant under salt stress.

Plant resistance to osmotic stress can be regulated through ABA-dependent and ABA-independent signaling pathways (Bharti et al. 2016). Besides P5CS1, ABAdependent osmotic regulation marker genes including COR15a, RD22 and ADH, and ABA-independent marker gene ERD1 were investigated in Arabidopsis and wheat with or without 3OC6-HSL treatment under saline and non-saline condition. COR15a belongs to late embryogenesis abundant protein (LEA) family and is important for plant tolerance to freezing-induced cellular dehydration (Sowemimo et al. 2019). COR15a contains $\mathrm{ABA}$ responsive element (ABRE) in several plant species (Kim 2006) and can be induced by ABA, cold and salinity (Zhu et al. 2017; Sowemimo et al. 2019). The promotor of $R D 22$ can be recognized by MYB/MYC transcription factors, which are induced by ABA, drought and salinity (Abe et al. 2003). Early Responsive to Dehydration Stress 1 (ERD1) encodes a ClpA (ATP binding subunit of the caseinolytic ATP-dependent protease) homologous protein and its promotor contains drought-responsive cis-element (DRE) that activated by NAC transcription factors under drought and salt stress (Tran et al. 2004). In present study, the expression of COR15a, RD22 and ERD1 were up-regulated by 3OC6-HSL in Arabidopsis and wheat under saline and non-saline condition (Fig. 5a, b, e). Furthermore, significant higher expression level of COR15a, RD22 and ERD1 in 3OC6-HSL-treated seedling was observed than in non-3OC6-HSL-treated seedling under salt stress condition (Fig. 5a, b, e). These result implicated that 3OC6-HSL regulated plant salt tolerance through not only ABA-dependent pathway but also ABAindependent pathway.

Plants minimize the harmful effects of ionic $\mathrm{Na}^{+}$stress by exclusion of $\mathrm{Na}^{+}$from leaf tissues and compartmentalization of $\mathrm{Na}^{+}$into vacuoles (Munns and Tester 2008; Blumwald 2000). SOS signaling pathway is a key mechanism for exclusion of $\mathrm{Na}^{+}$and ion homeostasis control at cellular level (Zhu 2000). SOS3, a calcium binding protein, is responsible for sensing calcium signals caused by salinity, and then dimerized and activated SOS2 serine/ threonine protein kinase. SOS2/SOS3 complex phosphorylated plasma membrane $\mathrm{Na}^{+} / \mathrm{H}^{+}$antiporter SOS1 resulting in $\mathrm{Na}^{+}$efflux (Zhu 2002; Munns and Tester 2008). SOS1 also regulates the transportation of $\mathrm{Na}^{+}$ from root to shoot to maintain appropriate $\mathrm{K}^{+} / \mathrm{Na}^{+}$ ratio in leaves (Qiu et al. 2002). Mutation studies show that SOS2/SOS3 complex is involved in negative regulation of AtHKT1 (Isayenkov and Maathuis 2019), which is responsible for $\mathrm{Na}^{+}$translocation to the shoot (Halfer et al. 2000). SOS2 can also interact with vacuolar $\mathrm{Na}^{+} / \mathrm{H}^{+}$ exchanger (NHX) antiporters and significantly elevate their exchange activity (Zhu 2002). In present study, the expression of SOS1, SOS2 and SOS3 were strong induced by 3OC6-HSL in Arabidopsis under both saline and nonsaline condition (Fig. 4g-i). What's more, significant higher expression level of SOS2 and SOS3 in 3OC6-HSLtreated seedling was observed than in non-3OC6-HSLtreated seedling under salt stress condition (Fig. 4h, i). Meanwhile, 3OC6-HSL reduced $\mathrm{Na}^{+}$contents significantly and maintained lower cytosolic $\mathrm{Na}^{+} / \mathrm{K}^{+}$ratio in Arabidopsis and wheat under salt stress condition 
(Fig. 4a, c, d, f). These results indicated that 3OC6-HSL could modulate cytosolic ion homeostasis by regulating SOS signal pathway under salt stress.

In summary, bacterial 3OC6-HSL can enhance plant salt tolerance. ABA-dependent and ABA-independent signal pathways and SOS signaling pathway might participate the regulation of salt tolerance by 3OC6-HSL in plants. It provides a new insight into the plant-microbe inter-communication. Salt stress in plant is a cumulative effect of osmotic and ionic stress which negative affects the plant growth and yield and multiple genes are involved in salt tolerance mechanism (Bharti et al. 2016). Further study should be conducted to clarify the molecular mechanism of a bacterial bioactive compound to improve plant growth and stress resistance. Molecular breeding and advanced biotechnology methods should help scientists to develop crops with enhanced salt tolerance (Deinlein et al. 2014). An AHL binding-Fe-CNF nanocomposite (NC) was successfully used as a nanobiofertilizer for stimulating seed germination and seedling growth, and developing resistance to oxidative and salinity stress and to fungal pathogenesis in chickpea (Gupta et al. 2019). Bacterial 3OC6-HSL is hopeful to apply as a biostimulant to promote crops growth and protect crops from salinity injury in agriculture production.

\section{Supplementary information}

Supplementary information accompanies this paper at https://doi. org/10.1186/s40529-020-00283-5.

Additional file 1: Table S1. Primer information of genes investigated in QRT-PCR.

\section{Acknowledgements}

Not applicable.

\section{Authors' contributions}

QZ performed phynotype analysis and qPCR analysis. XY performed biochemical and biophysical analysis. YL performed phynotype analysis and ionic measurement. QZ and XY drafted the manuscript. FL helped with QPCR analysis. XC helped with biochemical analysis. ZJ helped with statistical analysis of all data. SS was responsible for the design of the work and revised the manuscript. All authors read and approved the final manuscript.

\section{Funding}

This work was supported by the National Basic Research Program of China [Grant Number 2015CB150600]; and the National Natural Science Foundation of China [Grant Number 31601144 ].

\section{Availability of data and materials}

Not applicable

\section{Ethics approval and consent to participate} Not applicable.

\section{Consent for publication}

Not applicable.

\section{Competing interests}

The authors declare that they have no competing interests.

\section{Author details}

1 Biology Institute, Hebei Academy of Sciences, 46th South Street of Friendship, Shijiazhuang 050051, Hebei, China. ${ }^{2}$ College of Life Science, Hebei University, 180th East Road of Wusi, Baoding, China. ${ }^{3}$ Hebei Engineering and Technology Center of Microbiological Control on Main Crop Disease, 46th South Street of Friendship, Shijiazhuang, China.

Received: 6 December 2019 Accepted: 19 February 2020

Published online: 10 March 2020

\section{References}

Abe H, Urao T, Ito T, Seki M, Shinozaki K, Yamaguchi-Shinozaki K (2003) Arabidopsis AtMYC2 (bHLH) and AtMYB2 (MYB) function as transcriptional activators in abscisic acid signaling. Plant Cell 15:63-78

Arnon DI (1949) Copper enzymes in isolated chloroplasts: polyphenoloxidase in beta vulgaris. Plant Physiol 24:1-5

Ashraf M, Foolad MR (2007) Roles of glycine betaine and proline in improving plant abiotic stress resistance. Environ Exp Bot 59:206-216

Bai X, Todd CD, Desikan R, Yang Y, Hu X (2012) N-3-oxo-decanoyl-L-homoserine lactone activates auxin-induced adventitious root formation via hydrogen peroxide- and nitric oxide-dependent cyclic GMP signaling in mung bean. Plant Physiol 158:725-736

Barriuso J, Ramos Solano B, Fray RG, Cámara M, Hartmann A, Gutiérrez Mañero FJ (2008) Transgenic tomato plants alter quorum sensing in plant growthpromoting rhizobacteria. Plant Biotechnol J 6:442-452

Bates LS, Waldren RP, Teare ID (1973) Rapid determination of free proline for water-stress studies. Plant Soil 39:205-207

Bharti N, Pandey SS, Barnawal D, Patel VK, Kalra A (2016) Plant growth promoting rhizobacteria Dietzia natronolimnaea modulates the expression of stress responsive genes providing protection of wheat from salinity stress. Sci Rep 6:34768

Blumwald E (2000) Sodium transport and salt tolerance in plants. Curr Opin Cell Biol 12:431-434

Bose J, Rodrigo-Moreno A, Shabala S (2014) ROS homeostasis in halophytes in the context of salinity stress tolerance. J Exp Bot 65:1241-1257

Deinlein U, Stephan AB, Horie T, Luo W, Xu G, Schroeder JI (2014) Plant salttolerance mechanisms. Trans Plant Sci 19:371-379

Del Buono D, loli G, Nasini L, Proietti P (2011) A comparative study on the interference of two herbicides in wheat and italian ryegrass and on their antioxidant activities and detoxification rates. J Agric Food Chem 59:12109-12115

Dimkpa C, Weinand T, Asch F (2009) Plant-rhizobacteria interactions alleviate abiotic stress conditions. Plant, Cell Environ 32:1682-1694

Du Jardin P (2015) Plant biostimulants definition concept main categories and regulation. Sci Hortic 196:3-14

Gupta GS, Kumar A, Verma N (2019) Bacterial homoserine lactones as a nanocomposited fertilizer and defense regulator for chickpeas. Environ Sci Nano 6(4):1246-1258

Halfer U, Ishitani M, Zhu JK (2000) The Arabidopsis SOS2 protein kinase physically interacts with and is activated by the calcium-binding protein SOS3. Proc Natl Acad Sci USA 97:3735-3740

Ilangumaran G, Smith DL (2017) Plant growth promoting rhizobacteria in amelioration of salinity stress: a systems biology perspective. Front Plant Sci 8:1768

Isayenkov SV, Maathuis FJM (2019) Plant salinity stress: many unanswered questions remain. Front Plant Sci 10:80. https://doi.org/10.3389/ fpls.2019.00080

Jin G, Liu F, Ma H, Hao S, Zhao Q, Bian Z, Jia Z, Song S (2012) Two G-proteincoupled-receptor candidates, Cand 2 and Cand7, are involved in Arabidopsis root growth mediated by the bacterial quorum-sensing signals N-acyl-homoserine lactones. Biochem Biophys Res Commun 417:991-995

Kim SY (2006) The role of ABF family bZIP class transcription factors in stress response. Physiol Plant 126:519-527

Klein I, von Rad U, Durner J (2009) Homoserine lactones: do plants really listen to bacterial talk? Plant Signal Behav 4:50-51

Lata C, Jha S, Dixit V, Sreenivasulu N, Prasad M (2011) Differential antioxidative responses to dehydration-induced oxidative stress in core set of foxtail millet cultivars (Setaria italica L.). Protoplasma 248:817-828 
Liu F, Bian Z, Jia Z, Zhao Q, Song S (2012) The GCR1 and GPA1 participate in promotion of Arabidopsis primary root elongation induced by $\mathrm{N}$-acylhomoserine lactones, the bacterial quorum-sensing signals. Mol Plant Microbe Interact 25:677-683

Livak KJ, Schmittgen TD (2001) Analysis of relative gene expression data using real-time quantitative PCR and the 2(-Delta Delta C(T)) Method. Methods 25:402-408

Mathesius U, Mulders S, Gao M, Teplitski M, Caetano-Anolles G, Rolfe BG, Bauer WD (2003) Extensive and specific responses of a eukaryote to bacterial quorum-sensing signals. Proc Natl Acad Sci USA 100:1444-1449

Miao C, Liu F, Zhao Q, Jia Z, Song S (2012) A proteomic analysis of Arabidopsis thaliana seedling responses to 3-oxo-octanoyl-homoserine lactone, a bacterial quorum-sensing signal. Biochem Biophys Res Commun 427:293-298

Munns R (2002) Salinity, growth and phytohormones. In: Läuchli A, Lüttge U (eds) Salinity: environment-plants-molecules. Springer, Berlin, pp 271-290

Munns R, Tester M (2008) Mechanisms of salinity tolerance. Annu Rov Plant Biol 59:651-681

Murashige T, Skoog F (1962) A revised medium for rapid growth and bio assays with tobacco tissue cultures. Physiol Plant 15:473-497

Nakashima K, Kiyosue T, Yamaguchi-Shinozaki K, Shinozaki K (1997) A nuclear gene encoding a chloroplast-targeted Clp protease regulatory subunit homolog is not only induced by water stress but also developmentally up-regulated during senescence in Arabidopsis thaliana. Plant $J$ 12:851-861

Ortiz-Castro R, Martínez-Trujillo M, López-Bucio J (2008) N-acyl-L-homoserine lactones: a class of bacterial quorum-sensing signals alter postembryonic root development in Arabidopsis thaliana. Plant Cell Environ 31:1497-1509

Parsek MR, Val DL, Hanzelka BL, Cronan JE Jr, Greenberg EP (1999) Acyl homoserine-lactone quorum-sensing signal generation. Proc Natl Acad Sci USA 96:4360-4365

Passioura JB, Munns R (2000) Rapid environmental changes that affect leaf water status induce transient surges or pauses in leaf expansion rate. Aust J Plant Physiol 27:941-948

Pearson JP, Gray KM, Passador L, Tucker KD, Eberhard A, Iglewski BH, Greenberg EP (1994) Structure of the autoinducer required for expression of Pseudomonas aeruginosa virulence genes. Proc Natl Acad Sci USA 91:197-201

Qiu QS, Guo Y, Dietrich MA, Schumaker KS, Zhu JK (2002) Regulation of SOS1, a plasma membrane $\mathrm{Na}+/ \mathrm{H}+$ exchanger in Arabidopsis thaliana, by SOS2 and SOS3. Proc Natl Acad Sci USA 99:8436-8441

RankI S, Gunsé B, Sieper T, Schmid C, Poschenrieder C, Schröder P (2016) Microbial homoserine lactones (AHLs) are effectors of root morphological changes in barley. Plant Sci 253:130-140

Sahi C, Singh A, Blumwald E, Grover A (2006) Beyond osmolytes and transporters: novel plant salt-stress tolerance-related genes from transcriptional profiling data. Physiol Plant 127:1-9

Schikora A, Schenk ST, Stein E, Molitor A, Zuccaro A, Kogel KH (2011) $\mathrm{N}$-acyl-homoserine lactone confers resistance towards biotrophic and hemibiotrophic pathogens via alterd actication of AtMPK6. Plant Physiol 157:1407-1418

Shenk ST, Schikora A (2015) AHL-priming functions via oxylipin and salicylic acid. Front Plant Sci 5.784

Shenk ST, Hernández-Reyes C, Samans B, Stein E, Neumann C, Schikora M, Reichelt M, Mithöfer A, Becker A, Kogel KH, Schikora A (2014) N-acylhomoserine lactone primes plants for cell wall reinforcement and induces resistance to bacterial pathogens via the salicylic acid/oxylipin pathway. Plant Cell 26:2708-2723

Song S, Jia Z, Xu J, Zhang Z, Bian Z (2011) N-butyryl-homoserine lactone, a bacterial quorum-sensing signaling molecule, induces intracellular calcium elevation in Arabidopsis root cells. Biochem Biophys Res Commun 414:355-360
Sowemimo OT, Knox-Brown P, Borcherds W, Rindfleisch T, Thalhammer A, Daughdrill GW (2019) Conserved glycines control disorder and function in the cold-regulated protein, COR15A. Biomolecules 9:E84

Székely G, Abrahám E, Cséplo A, Rigó G, Zsigmond L, Csiszár J, Ayaydin F, Strizhov N, Jásik J, Schmelzer E, Koncz C, Szabados L (2008) Duplicated P5CS genes of Arabidopsis play distinct roles in stress regulation and developmental control of proline biosynthesis. Plant J 53:11-28

Tiwari S, Prasad V, Chauhan PS, Lata C (2017) Bacillus amyloliquefaciens confers tolerance to various abiotic stresses and modulates plant response to phytohormones through osmoprotection and gene expression regulation in rice. Front Plant Sci 8:1510

Tran LS, Nakashima K, Sakuma Y, Simpson SD, Fujita Y, Maruyama K, Fujita M, Seki M, Shinozaki K, Yamaguchi-Shinozaki K (2004) Isolation and functional analysis of Arabidopsis stress-inducible NAC transcription factors that bind to a drought-responsive cis-element in the early responsive to dehydration stress 1 promoter. Plant Cell 16:2481-2498

Verbruggen N, Hermans C (2008) Proline accumulation in plants: a review. Amino Acids 35:753-759

Verslues PE, Agarwal M, Katiyar-Agarwal S, Zhu J, Zhu JK (2006) Methods and concepts in quantifying resistance to drought, salt and freezing, abiotic stresses that affect plant water status. Plant J 45:523-539

von Rad U, Klein I, Dobrev PI, Kottova J, Zazimalova E, Fekete A, Hartmann A, Schmitt-Kopplin P, Durner J (2008) Response of Arabidopsis thaliana to $\mathrm{N}$-hexanoyl-DL-homoserine lactone, a bacterial quorum sensing molecule produced in the rhizosphere. Planta 229:73-85

Xiong L, Ishitani M, Lee H, Zhu JK (2001) The Arabidopsis LOS5/ABA3 locus encodes a molybdenum cofactor sulfurase and modulates cold stressand osmotic stress-responsive gene expression. Plant Cell 13:2063-2083

Yang J, Kloepper JW, Ryu CM (2009) Rhizosphere bacteria help plants tolerate abiotic stress. Trends Plant Sci 14:1-4

Zhang H, Kim MS, Sun Y, Dowd SE, Shi H, Paré PW (2008) Soil bacteria confer plant salt tolerance by tissue-specific regulation of the sodium transporter HKT1. Mol Plant Microbe Interact 21:737-744

Zhang Z, Mao C, Shi Z, Kou X (2017) The amino acid metabolic and carbohydrate metabolic pathway play important roles during salt-stress response in tomato. Front Plant Sci 8:1231

Zhao Q, Zhao YJ, Zhao BC, Ge RC, Li M, Shen YZ, Huang ZJ (2009) Cloning and functional analysis of wheat $\mathrm{V}-\mathrm{H}^{+}$-ATPase subunit genes. Plant Mol Biol 69:33-46

Zhao Q, Zhang C, Jia Z, Huang Y, Li H, Song S (2015) Involvement of calmodulin in regulation of primary root elongation by $\mathrm{N}$-3-oxo-hexanoyl homoserine lactone in Arabidopsis thaliana. Front Plant Sci 5:807

Zhao Q, Li M, Jia Z, Liu F, Ma H, Huang Y, Song S (2016) AtMYB44 positively regulates the enhanced elongation of primary roots induced by $\mathrm{N}-3-\mathrm{OXO}-$ hexanoyl homoserine lactone in Arabidopsis thaliana. Mol Plant Microbe Interact 29:774-785

Zhu JK (2000) Genetic analysis of plant salt tolerance using Arabidopsis. Plant Physiol 124:941-948

Zhu JK (2002) Salt and drought stress signal transduction in plants. Annu Rov Plant Biol 53:247-273

Zhu Y, Wang B, Tang K, Hsu CC, Xie S, Du H, Yang Y, Tao WA, Zhu JK (2017) An Arabidopsis nucleoporin NUP85 modulates plant responses to ABA and salt stress. PLoS Genet 13:e1007124

Zou P, Lu X, Zhao H, Yuan Y, Meng L, Zhang C, Li Y (2019) Polysaccharide derived from the brown algae Lessonia nigrescens enhance salt stress tolerance to wheat seedlings by enhancing the antioxidant system and modulating intracellular ion concentration. Front Plant Sci 10:48

\section{Publisher's Note}

Springer Nature remains neutral with regard to jurisdictional claims in published maps and institutional affiliations. 